\title{
Theories of ethics and perception of symptoms: A diabetes perspective
}

This editorial delves into a hitherto unexplored facet of diabetology. The aim of this communication is to encourage cross-discipline fertilization in this field, making it more robust and responsive to the needs of persons with diabetes.

Diabetes is a heterogenous disorder characterized by varied etiopathogenic mechanisms, associations, clinical presentations, and complications. This diversity is further enhanced by an equally wide array of therapeutic and diagnostic procedures. This diversity results in and gets reflected in variations in the clinical care. The fact that diabetes is not merely a biological entity, but a syndrome that perfectly fits the biopsychosocial health model, makes this metabolic disease and its management even more complex. This theory posits that psychological and social factors contribute to health and disease in tandem with biological determinants. ${ }^{[1]}$

In spite of enhanced understanding in the psychosocial modulators of diabetes, researchers and clinicians often find it challenging to explain variations in behavior of people with diabetes. Similarly, the management patterns followed by diabetes care professionals are, at times, difficult to understand and explain. People with diabetes exhibit varying attitudes and behavior patterns related to health-care seeking, acceptance of modern medical care, and adherence to prescribed therapy. While all these aspects of diabetes care can be understood through psychosocial explanations, some unique features of diabetology merit a wider, and even deeper, analysis.

The same biological abnormality underlying a disease often manifests differently symptomatically. In addition, similar symptomatology tends to get perceived differently across patients. Consequently, different patients tend to have different illness behavior. ${ }^{[2]}$ Interestingly, patients with apparently similar disease parameters (viz., glucose control indicators, and duration of illness) can react differently to their illness experience. This variation is reflected in help-seeking behavior as well. ${ }^{[3]}$ In context of diabetes, this variation is noted in both acute and chronic complications such as hypoglycemia and peripheral neuropathy. Symptoms of hypoglycemia are reported in contrasting manner by patients from different cultural and linguistic backgrounds. Similarly, symptoms of chronic complications such as peripheral neuropathy can be described by a seemingly never-ending list of adjectives.

This clinical heterogeneity is most obvious for hypoglycemia. Hypoglycemia, an integral component of diabetes, is characterized by a wide array of symptoms. Some individuals present with more "complaints per unit biochemical abnormality," while others carry a noncomplaining attitude (reflected in "asymptomatic" presentation); in spite of major biochemical defects. Much of this paradox can be explained by biomedical dysfunction such as hypoglycemia unawareness and by psychosocial determinants such as personality traits and coping styles. ${ }^{[4]}$ However, not all the variance noted in symptomatology perception fits existing "strait jacket" explanations.

Human attitudes and behaviors are shaped by an ongoing interaction of various biological, psychological, and environmental factors. Cognitive, psychodynamic, behavioral, and interpersonal paradigms are commonly used to explain these attitudes and behaviors. However, role of ethics in shaping these attitudes and behaviors remains rather unexplored. Ethical perspectives of illness behavior, and help seeking, find little, if any, application in clinical settings.

This editorial highlights certain theories of ethics, relevant to health care, which may explain the clinical paradoxes noted in diabetes care praxis. While being of special relevance to hypoglycemia, these theories can help understand patients' and physicians' attitudes and behaviors with regard to other aspects of diabetes care as well.

\section{DEONTOLOGY}

Deontology is a theory of ethics that places value on intention of a person performing a particular act, rather than the outcome. ${ }^{[5]}$ Hence, an adverse outcome such as hypoglycemia will be excused as long as the prescriber's intentions were "good" while prescribing a particular antidiabetic treatment.

Deontology also requires absolute adherence to system and processes including treatment. It focuses on rules, 
regulations, obligation, and duties. Thus, a patient who subscribes to deontology as an ethical principle will be adherent to prescribed medical as well as nonpharmacological intervention. In addition, the patient is likely to complain less often about hypoglycemia, considering these symptoms to be an integral or unavoidable part of diabetes, or diabetes therapy. Even when perceived, symptoms of hypoglycemia may be reported in a "nonserious" or casual manner. As a consequence of this approach on part of the patient, even an astute clinician may struggle to understand and respond appropriately to the situation. On the other hand, from the perspective of diabetes care providers, application of deontological principles will expect people with diabetes to comply with their medication without complaining. Subtle symptoms of hypoglycemia may not be appreciated and addressed. In fact, these may be dismissed in a nonempathic manner, leading to suboptimal patient-therapist bonding and poor therapeutic outcomes.

\section{CONSEQUENTIALISM}

Consequentialism is an ethical framework which keeps the consequence or outcome of any action at center stage. This assesses work or action in terms of collective outcome and accepts interventions if the results are of collective/community benefit. Actions which are contrary to right of individuals (if in collective good of the community at large) are accepted as an inevitable part of consequentialism-based interventions. Utilitarianism is a theory of normative ethics which is a form of consequentialism. ${ }^{[5]}$ A consequentialism-based diabetes practice will place more value on the use of group-based counseling and educational classes, rather than face-to-face individualized counseling. The patient and physician, however, may tend to view success in diabetes control from a glycated hemoglobin-centric point of view, at the cost of other (equally important) biological and psychological parameters. At the same time, the consequentialist living with diabetes may exhibit extreme inertia in therapy intensification due to fear to hypoglycemia.

\section{VIRTUISM}

Virtues, or embedded character traits, define ethics for many people. Virtue ethics assumes that people with good character perform good acts and do not focus on the outcome. ${ }^{[6]} \mathrm{A}$ patient who believes in virtue ethics will accept complications of diabetes as long as the physician has behaved in a patient-friendly or "virtuous" manner. A physician who follows virtuism will have a clinical style responsive to patient symptomatology. The decision-making in such a practice will be psychosocial centeric rather than biomedical-centric. Hypoglycemia will be accepted as an augmented adverse drug reaction and will not be considered a barrier to acceptance of therapy.

\section{PRINCIPLISM}

Principlism is a novel theory of ethics which tries to explain behavior through four cardinal principles - autonomy, nonmaleficence, beneficence, and justice. ${ }^{[7]}$ The four pillars of principlism stimulate the patients to empower themselves through various educational and support systems, to participate actively in shared decision-making, and to exhibit optional health-care seeking. These principles encourage the diabetes care provider to follow patient-centered care in the true sense of the concept while practicing shared decision-making and ensuring equipoise with the patient. They also encourage the physician to follow a "safety first" paradigm while prescribing drugs and to prefer medicines that are safer and better tolerated. Principlism, therefore, facilitates modern diabetes care and helps minimize risks such as hypoglycemia.

\section{PRAGMATIC ETHICS}

Pragmatic ethics believes in the progress of society in the field of both science and morals. Pragmatic scientists, in both medical and social disciplines, agree with certain proven facts of life but understand that these facts may be disproven later. Individuals with diabetes who believe in pragmatism will accept their condition, and also the medication provided, but will continuously strive to improve their condition. In some cases, this may take the form of "doctor shopping" which may be actually a pragmatic step in case diabetes is not under control.

\section{ETHICAL EGOISM}

Ethical egoism ${ }^{[8]}$ is a perspective which when applied to people with diabetes and diabetes care professional states that they should do what is in their self-interest. While people with diabetes who subscribe to ethical egoism prefer patient-centered approach to their management, physicians with this ethical architecture may prefer to practice evidence-based medicine. Ethical egoism may present as a barrier to appropriate diabetes management, that is, it hinders optimal patient-provider communication and understanding.

\section{CONCLUSION}

The study of medical ethics is well established as a distinct science of medicine. The four principles of medicine 
ethics embodied in principlism have been utilized in many health-care settings. However, theories of ethics have not been extrapolated to the understanding of diabetes care to the desired extent. Use of different ethical principles and approaches can help understand important aspects of doctor-patient relationship. These principles can help understand expectations and reactions of the patients as well as therapists with respect to various aspects of diabetes care.

\section{Sanjay Kalra, Yatan Pal Singh Balhara ${ }^{1}$, Manash P. Baruah ${ }^{2}$}

Department of Endocrinology, Bharti Hospital, Karnal, Haryana, ${ }^{1}$ Department of Psychiatry, National Drug Dependence Treatment Center, All India Institute of Medical Sciences, New Delhi, ${ }^{2}$ Department of Endocrinology, Excel Center (Initiative of Excelcare Hospitals Pvt. Ltd.), Guwahati, Assam, India

Address for correspondence: Dr. Sanjay Kalra, Department of Endocrinology, Bharti Hospital, Karnal, Haryana, India. E-mail: brideknl@gmail.com

Received: 30.07.2017, Accepted: 30.07.2017

\section{REFERENCES}

1. Engel GL. The need for a new medical model: A challenge for biomedicine. Science 1977;196:129-36.

2. Pilowsky I. Abnormal illness behaviour. Br J Med Psychol 1969;42:347-51.
3. Cornally N, McCarthy G. Help-seeking behaviour: A concept analysis. Int J Nurs Pract 2011;17:280-8.

4. Kalra S, Kalra B, Agrawal N, Sahay R, Unnikrishnan A, Chawla R. Coping strategies in diabetes. Internet J Geriatr Gerontol 2010;5.

5. Conway P, Gawronski B. Deontological and utilitarian inclinations in moral decision making: A process dissociation approach. J Pers Soc Psychol 2013;104:216-35.

6. Allmark P. Virtue and austerity. Nurs Philos 2013;14:45-52.

7. Gillon R. Medical ethics: Four principles plus attention to scope. BMJ 1994;309:184-8.

8. Daniels CB. A note on ethical egoism. Philos Stud 1972;23:418-20.

This is an open access journal, and articles are distributed under the terms of the Creative Commons Attribution-NonCommercial-ShareAlike 4.0 License, which allows others to remix, tweak, and build upon the work non-commercially, as long as appropriate credit is given and the new creations are licensed under the identical terms.

For reprints contact: reprints@medknow.com

\section{Access this article online}

\begin{tabular}{|l|l|}
\hline \multicolumn{2}{|c|}{ Access this article online } \\
\hline Quick Response Code: & Website: \\
\hline & www.joshd.net \\
\cline { 2 - 2 } & DOI: \\
& 10.4103/joshd.J_Soc_Health_ \\
& Diabetes_21_17 \\
\hline
\end{tabular}

How to cite this article: Kalra S, Balhara YP, Baruah MP. Theories of ethics and perception of symptoms: A diabetes perspective. J Soc Health Diabetes 2018;6:1-3. 